\title{
Is Group Physical Therapy in the Circuit Format a Model of Cardiovascular Conditioning in Parkinson's Disease?
}

\author{
Augusto CC*, Alice HM, Guilherme YT, Caroline NG, Silas de \\ Oliveira D, Andressa SP, Katiane MG, Mileide CS, Larissa BA, Carla \\ de Oliveira C, Lucia MB, and Roselene MRL \\ Faculdade de Ciências e Tecnologia (FCT), campus de Presidente Prudente, \\ Universidade Estadual Paulista “Júlio de Mesquita Filho" (UNESP), Brazil
}

Research Article

Volume 3 Issue 1

Received Date: June 15, 2018

Published Date: August 09, 2018

*Corresponding author: Augusto Cesinando de Carvalho, Faculdade de Ciências e Tecnologia (FCT), Universidade Estadual Paulista “Júlio de Mesquita Filho" (UNESP), Rua: Antônio Aranda, no110, Álvares Machado - São Paulo - Brazil, Tel: 18981377168; Email: augusto.cesinando@unesp.br

\section{Abstract}

Introduction: In order to decline the progression of signs and symptoms and improve the functional condition of parkinsonians, physical exercise is important during rehabilitation, being intensity a relevant factor. However, still unclear whether group physiotherapy in the circuit format (CF) is capable of triggering better conditioning and positive cardiovascular changes in parkinsonians.

Objective: To analyze the heart rate performance in Parkinsonians submitted to CF and correlate with the functional capacity to evaluate the effectiveness of the group physiotherapy in circuit format as a conditioning method.

Material and Methods: Parkinsonians of both men and women, with Hoehn and Yahr between 1 and 3 participated in CF. Participants were submitted to an initial evaluation, in which Time Up and Go (TUG) were applied and Berg Balance Scale (BSE). After that, the blood pressure was measured, the cardiofrequencimetre device was placed and the participants were directed to the CF session, which consists of the practice of exercises in 10 different stations, assembled with sticks, chairs, ladder, ramp, cones, elastic tube and sign maps. The time station was 2 minutes and the total duration of each CF session was 50 minutes.

Results: There was a significant difference when compared to BHR with MHR in each season, and training intensity provided by $\mathrm{CF}$ to parkinsonians was classified as very light and mild. In addition, there was no correlation between the values of MHR with TUG and BSE during CF. 


\section{Neurology \& Neurotherapy Open Access Journal}

Conclusion: The performance of parkinsonians submitted to CF was not able to perform cardiovascular conditioning, nor was there correlation with the functional capacity.

Keywords: Parkinson Disease; Physical Therapy Specialty; Circuit-Based Exercise; Heart Rate

Abbreviations: PD: Parkinson's Disease; HRR: Heart Rate Reserve; MHR: Maximal Heart Rate; CF: Circuit Format; BSE: Berg Balance Scale; TUG: Time Up and Go.

\section{Introduction}

Parkinson's disease (PD) is characterized by a progressive neurodegenerative disorder considered the second most common in the world and responsible for the loss of functional independence [1] over time due to bradykinesia, stiffness, tremor, postural instability and imbalance, which leads to a decrease in physical activity and sedentary lifestyle [2]. Thus, due to this clinical condition, there is a progressive incapacitation of mobility and daily activities that can lead to social isolation and decrease of the quality of life, besides generating occupational and socioeconomic problems [3].

Strategies to improve functional condition and decline the progression of PD signs and symptoms should be performed and physical exercise is a primary factor in the rehabilitation of these patients [4-7] and exercise programs such as strength training and aerobic conditioning have the best results in relation to the motor skills with neurological sequels [8]. The intensity of performance is important, being evaluated by the amount of repetition of the specific movement and the time dedicated to practice among other aspects.

The intensity of cardiovascular training is typically defined as the percentage of maximal heart rate (MHR), heart rate reserve (HRR) or VO2max. Values below 20\% HRR determine very light training, between 20-39\% light, while $40-59 \%$ moderate and $60-84 \%$ strong, greater than or equal to $85 \%$ of the HRR are considered very strong training and $100 \%$ maximum [9].

The intensity of conventional physiotherapy programs is less than 30\% HRR, and thus contributes to low levels of cardiorespiratory fitness; therefore, increasing the exercise intensity during the rehabilitation programs is useful [9-13].

Among the intervention possibilities there is evidence that group physical therapy in the circuit format (CF) is able to improve the functional capacity of neurological patients [14]. This therapy is a model that uses active exercises in which specific functional tasks are performed intensively and that differs from conventional physiotherapy due to group format, focus on the repetition and continuous progression of functional exercises in a series of activities stations arranged in a circuit format aiming to improve the general mobility [15].

However, it is not clear that a CF is able to trigger better conditioning and positive cardiovascular changes in Parkinsonians. Thus, studies involving the behavior of heart rate make important modeling aspects for therapeutic protocols in Parkinsonians. So, the objective was to analyze the heart rate performance of Parkinsonians and correlating with the functional capacity to evaluate the effectiveness of the circuit format as a conditioning method.

\section{Material and Methods}

For the accomplishment of this transversal case reports, patients diagnosed with PD were enrolled in CF at the Center for Studies and Assistance in Physiotherapy and Rehabilitation (CEAFIR) of the Faculty of Sciences and Technology of the Paulista State University (UNESP). All Parkinsonians were informed about the objectives and procedures of the study and signed the free and informed consent form approved by the Research Ethics Committee of the Institution.

Subjects with clinical diagnosis of PD, both men and women and with Hoehn \& Yahr [16] between 1 and 3 were included in the study. Parkinsonians with cognitive deficits evaluated by the Mini Mental State Examination (MMSE) [17], Hoehn and Yahr 4 and 5, or that present other neurological, rheumatic or orthopedic diseases were excluded.

The Parkinsonians were submitted to an initial evaluation, in which functional instruments and scales were used to investigate functional motor parameters, such as: Time Up and Go (TUG) [18] to evaluate functional mobility and gait and the Berg Balance Scale (BSE) [19], in order to evaluate the dynamic and static balance. 


\section{Neurology \& Neurotherapy Open Access Journal}

After that, the blood pressure was measured, the cardiofrequencimetre device was placed and the Parkinsonians were directed to the CF session, which consists of the practice of exercises in 10 different stations, assembled with sticks, chairs, ladder, ramp, cones, elastic tube and sign maps Table 1.

\begin{tabular}{|c|c|}
\hline $\begin{array}{c}\text { Station } \\
\text { Number }\end{array}$ & Description of Exercises \\
\hline Station 1 & $\begin{array}{c}\text { Flexion and extension of hip and } \\
\text { alternating and supporting the feet on a } \\
\text { 19.68 inches height }\end{array}$ \\
\hline Station 2 & $\begin{array}{c}\text { Flexion and extension of shoulder } \\
\text { associated with trunk rotation in } \\
\text { orthostatic position }\end{array}$ \\
\hline Station 3 & $\begin{array}{c}\text { Flexion and extension of shoulder with } \\
\text { resistance using elastic band }\end{array}$ \\
\hline Station 4 & $\begin{array}{c}\text { Flexion and extension of hip, knee and } \\
\text { ankle (squatting) on a 7.87 inches step. } \\
\text { The individual can support on a bar }\end{array}$ \\
\hline Station 5 & $\begin{array}{c}\text { Gait - walk a distance of 5 meter and } \\
\text { return to starting position }\end{array}$ \\
\hline Station 6 & $\begin{array}{c}\text { Transfer plastic bottles weighing 1 kg } \\
\text { from a shelf 19.68 inches from the floor } \\
\text { to 47.24 inches and vice versa }\end{array}$ \\
\hline Station 7 & $\begin{array}{c}\text { Flexion and extension of shoulder, elbow } \\
\text { and wrist using a cycle ergometer with } \\
\text { minimum resistance }\end{array}$ \\
\hline Station 8 & $\begin{array}{c}\text { Lateral gait on the parallel bar with } \\
\text { obstacles 1.96 inches high apart 11.81 } \\
\text { inches. The patient can support on the } \\
\text { bar }\end{array}$ \\
\hline Station 9 & $\begin{array}{c}\text { Climb the stairs then down a ramp and } \\
\text { vice versa }\end{array}$ \\
\hline Station 10 & $\begin{array}{c}\text { Go up and down one step. The patient } \\
\text { may support on a bar }\end{array}$ \\
\hline
\end{tabular}

Table 1: Description of the exercises performed in the stations.

The time of station was 2 minutes, with each Parkinsonian performing the exercise at their speed, but also an increasingly fast execution, according to the gain of physical conditioning and respecting the limits of each Parkinsonian. The total duration of each CF session was 50 minutes.

Heart rate (HR) analysis was used for the cardiofrequencimetre monitor Polar ${ }^{\circledR}$ RS800CX (Polar Electric OY, Finland) during the $\mathrm{CF}$ session. The device consists of an adjustable elastic chest strap and a HR transmitter. The elastic strap consists of two electrodes mounted on a sealed electronic transmitter that was positioned in the volunteers' chest at the level of the distal third of the sternum (positioned on the sternal manubrium and in the region of the fifth left intercostal space), using an elastic strap. These telemetric units obtained the electrical impulses from the heart and transmitted this information by means of an electromagnetic field to the monitor (clock) that was in the right hand of the volunteers.

Before starting the CF session, the basal HR (BHR), who were seated and oriented to remain in rest with spontaneous breathing for 10 minutes, were captured. After this period, the HR uptake continued through all the stations of the circuit, until the end of the session. The data obtained through monitoring were transferred from the cardiofrequencimetre to the computer using software Polar ProTrainer 5 (version 5.41.002).

For determination of the BHR, the value recorded in the cardiofrequencimetre at the end of the 10 minutes of rest in the sitting position was used. The mean HR (MHR) was obtained by the average of the duration of the $\mathrm{CF}$ and the maximum HR (HRmax) was the highest HR founded during the $\mathrm{CF}$.

The maximum HR (HRmax) was obtained by the following equation: HRmax $=220-$ age [20]. In the case of volunteers who used beta-blockers for the control of arterial hypertension HRmax was corrected by equation: $\%$ HR to correct = beta-blocker $(\mathrm{mg})+95.58 / 9.74$ [21] .

To calculate the training HR (THR), the intensity was calculated during the $\mathrm{CF}$ session using the heart rate reserve (HRR) method, defined by equation: THR = ([HRmax - HRR] x \%Intensity) + BHR [22]. Using these equations, the training intensity during the $\mathrm{CF}$ session was determined and classified by the percentage of HRmax [9].

For data analysis, initially the information was tabulated in Microsoft Office Excel Professional Plus (2013). Descriptive statistics were then performed to characterize the population profile, to write the values obtained in the functional tests and the training intensity during the session by means of the HRR percentages, the data presented in values of mean and standard deviation.

To correlate the results obtained in the functional tests with the values of average heart rate during the $\mathrm{CF}$ and the maximum heart rate, initially the normality of the data was tested by the Shapiro-Wilk test followed by the correlation of Pearson or Spearman. 


\section{Neurology \& Neurotherapy Open Access Journal}

Additionally, to investigate the difference between BHR and MHR at each station, normality was also assessed by the Shapiro-Wilk test followed by paired Ttest or Wilcoxon test. All analyzes were performed using Statistical Package for Social Sciences (version 22.0, SPSS inc., Chicago, Il) and significance was set at $5 \%$.

\section{Results}

The study included 08 PD patient's male with an average age of $73.13 \pm 8.42$ years old. The analysis of the TUG values revealed a time of $11.12 \pm 2.31$ seconds of execution and of the BSE $52.50 \pm 3.38$ points.

The results that investigated the correlation between the functional tests and MHR values during CF and HRmax showed that there was no statistically significant difference (TUG vs. MHR: $\mathrm{p}=0.88 ; \mathrm{R}=-0.06$; HRmax: $\mathrm{p}=$ $0.86, R=0.07$ and BSE vs. MHR: $p=0.87, R=0.06$, BSE vs. HRmax: $p=0.63, R=0.20$ ). The results to investigate the difference between the HRR and MHR in each station are shown in Table 2.

\begin{tabular}{|c|c|c|}
\hline & Mean \pm SD & $\begin{array}{c}\text { Minimum- } \\
\text { Maximum Values }\end{array}$ \\
\hline BHR & $74.50 \pm 10.50$ & {$[60-87]$} \\
\hline HR_1E & $79.87 \pm 13.67^{*}$ & {$[65-94]$} \\
\hline HR_2E & $82.37 \pm 12.47^{*}$ & {$[64-99]$} \\
\hline HR_3E & $81.12 \pm 10.24^{*}$ & {$[65-98]$} \\
\hline HR_4E & $86.87 \pm 11.96^{*}$ & {$[67-102]$} \\
\hline HR_5E & $87.75 \pm 10.68^{*}$ & {$[66-101]$} \\
\hline HR_6E & $87.62 \pm 11.26^{*}$ & {$[68-100]$} \\
\hline HR_7E & $90.12 \pm 12.69^{*}$ & {$[69-101]$} \\
\hline HR_8E & $86.00 \pm 10.59^{*}$ & {$[68-99]$} \\
\hline HR_9E & $87.00 \pm 10.87^{*}$ & {$[68-100]$} \\
\hline HR_10E & $91.12 \pm 12.49^{*}$ & {$[68-105]$} \\
\hline MHR & $85.01 \pm 11.88$ & {$[62-97]$} \\
\hline HRmax & $147.25 \pm 8.34$ & {$[139-165]$} \\
\hline
\end{tabular}

BHR: Basal Heart Rate; HRmax: Maximum Heart Rate during CF station; MHR: Mean Heart Rate during CF station; N: Number of participants; *Difference in relation to rest by means of the $\mathrm{T}$ test for paired data; \#Difference from rest by the Wilcoxon test; $\mathrm{p}<0.05$.

Table 2: Mean values followed by their respective standard deviation and heart rate of study participants (n $=8)$.

Thus, there was a significant difference when compared to BHR with MHR in each station. In addition, five participants presented a percentage of the HRR during the CF below $20 \%$ of the THR $(78 \pm 9.10 \mathrm{bpm})$, three participants presented intensity between $20-39 \%$ of the THR $(97.03 \pm 2.70 \mathrm{bpm})$. These values revealed that $62 \%$ of the participants, that is, the majority presented the intensity of the training performed very light and the remaining 38\% presented the intensity range of the light training.

\section{Discussion}

In this case reports the results showed that the intensity training provided by the CF to the parkinsonians was classified as very light and light, that is, there was a low intensity exercises, being this finding similar to those found in relation to conventional physiotherapy, whose therapies are generally insufficient to contribute improvements in cardiorespiratory fitness [10].

Parkinsonians have motor impairments and also in the autonomic nervous system $[23,24]$ due to neuronal changes triggered by the disease, as well as damage to the autonomic centers of the brain, such as the hypothalamus, basal ganglia, reticular formation, and the dorsal nucleus of the vagus, which as a consequence may lead to cardiovascular dysregulation [25] characterized mainly by reductions in sympathetic and parasympathetic activities [23]. In addition, there is the report of lower HRmax in parkinsonians compared to individuals without PD when under stress [26,27]. However, still unclear whether the HR behavior is interfered with due to physiological changes or due to some intervention, as there are methodological differences in some studies despite interesting results on cardiovascular fitness in Parkinsonians [23].

The present study did not demonstrate a correlation between the HRmax and the functional capacity of parkinsonians determined by the tests. In view of these findings, it was considered that the functional incapacity of these individuals did not influence the cardiovascular responses [28], perhaps the motor incapacity prevented the participants from performing the exercises in the intensity that was proposed and there was no overload in the cardiovascular system or even due to the autonomic changes the responses become impaired and for that, larger overloads in a CF should be imposed.

When we consider that the intervention through the $\mathrm{CF}$ allows the parkinsonians to perform the functional activities of daily living independently, it was expected a considerable increase of MHR and HRmax, but this was not observed. As the intensity of the exercise can directly influence the result of the training of the individuals, it is believed that the training with activities of mild and 


\section{Neurology \& Neurotherapy Open Access Journal}

moderate intensity can contribute to the maintenance of functional activities such as gait and quality of life [29], however for a cardiovascular conditioning high-intensity exercises would be more beneficial [30]. The relevance of therapeutic programs can be reinforced if they attempt to control the intensity of therapy to improve conditioning.

It is important to note that the $\mathrm{CF}$ showed a progressive increase of MHR at each station, compared to BHR, and although this cardiac response was low, it reveals that exercise is better than keeping the patient at home, exposed to functional immobility causing a sedentary lifestyle and its consequences.

The proposal of the CF is to provide an environment capable of maintaining this active population, promoting motor learning and retention of the task, as well as social integration and physical activities to maintain balance and gait [31] of CF were proposed based on daily activities and that these could lead to benefits in the practical life activities of this population. Because they are tasks that individuals perform daily, probably performing these exercises were not able to achieve an intensity of aerobic training.

This research identified the need for further studies with the CF intervention in parkinsonians, mainly related to the intensity appropriate for favorable cardiovascular effects. It is possible to identify research models with aerobic training in parkinsonians, but aimed at different objectives [29,30,32]. Thus, the analysis of the effectiveness of the training circuit as a method of conditioning becomes relevant due to the lack of the subject in the literature; however, this analysis in a restricted number of participants is a limitation of this study [31].

This case reports provides a preliminary evidence the analysis and knowledge of the performance of the CF providing by the peculiar therapy, with the intention of influencing and emphasizing the importance of this attitude before the other protocols of rehabilitation. Besides, suggests future trials with a larger sample and emphasizing the importance of the topic in the opposite of the insufficiency of studies on the same.

\section{Conclusion}

With the results of this research, it can be concluded that the performance of parkinsonians submitted to $\mathrm{CF}$ was classified as very light and light due to the low intensity of the exercises performed and therefore not able to perform cardiovascular conditioning, associated with a lack of correlation with the functional capacity.

\section{References}

1. Schapira AH (2009) Neurobiology and treatment of Parkinson's disease. Trends Pharmacol Sci 30(1): 4147.

2. Nimwegen VM, Speelman AD, Rossum HEJ, Overeem S, Deeg DJ, et al. (2011) Physical inactivity in Parkinson's disease. J Neurol 258(12): 2214-2221.

3. Allen NE, Sherrington C, Paul SS, Canning CG (2011) Balance and falls in Parkinson's disease: a metaanalysis of the effect of exercise and motor training. Mov Disord 26(9): 1605-1615.

4. Dirnberger G, Jahanshahi M (2013) Executive dysfunction in Parkinson's disease: a review. J Neuropsychol 7(2): 193-224.

5. Paula FR, Lima LO, Salmela LFT, Luci FTS, Cardoso F (2011) Exercício aeróbio e fortalecimento muscular melhoram o desempenho funcional na doença de Parkinson. Fisioter Mov 24(3): 379-388.

6. Crizzle AM, Newhouse IJ (2006) Is physical exercise beneficial for persons with Parkinson's disease? Clin J Sport Med 16(5): 422-425.

7. Dibble LE, Addison O, Papa E (2009) The effects of exercise on balance in persons with Parkinson's disease: a systematic review across the disability spectrum. J Neurol Phys Ther 33(1): 14-26.

8. Bherer L, Erickson KI, Liu-Ambrose T (2013) A review of the effects of physical activity and exercise on cognitive and brain functions in older adults. J Aging Res 657508.

9. Mezzani A, Hamm LF, Jones AM, McBride PE, Moholdt T, et al. (2013) Aerobic exercise intensity assessment and prescription in cardiac rehabilitation: a joint position statement of the European Association for Cardiovascular Prevention and Rehabilitation, the American Association of Cardiovascular and Pulmonary Rehabilitation and the Canadian Association of Cardiac Rehabilitation. Eur J Prev Cardiol 20(3): 442-467.

10. MacKay-Lyons MJ, Makrides L (2002) Cardiovascular stress during a contemporary stroke rehabilitation program: is the intensity adequate to induce a 


\section{Neurology \& Neurotherapy Open Access Journal}

training effect? Arch Phys Med Rehabil 83(10): 13781383.

11. Mavrommati F, Collett J, Franssen M, Meaney A, Sexton C, et al. (2017) Exercise response in Parkinson's disease: insights from a cross-sectional comparison with sedentary controls and a perprotocol analysis of a randomised controlled trial. BMJ Open 7(12): e017194.

12. Kanegusuku H, Batista CS, Peçanha T, Nieuwboer A, Silva ND Jr, et al. (2017) Effects of Progressive Resistance Training on Cardiovascular Autonomic Regulation in Patients With Parkinson Disease: A Randomized Controlled Trial. Arch Phys Med Rehabil 98(11): 2134-2141.

13. Kuys SS, Brauer SG, Ada L (2011) Higher-intensity treadmill walking during rehabilitation after stroke in feasible and not detrimental to walking pattern or quality: a pilot randomized trial. ClinRehabil 25(4): 316-326.

14. English C, Hillier SL (2010) Circuit class therapy for improving mobility after stroke. Cochrane Database Syst Rev (7): CD007513.

15. Carvalho AC, Pereira AS, Oliveira MCS, Franco MR (2018) Fisioterapia em grupo no formato de circuito de treinamento pós-acidente vascular cerebral. In: Associação Brasileira de Fisioterapia Neurofuncional; Garcia CSNB, Facchinetti LD, organizadoras. PROFISIO Programa de Atualização em Fisioterapia Neurofuncional: Ciclo 5. Porto Alegre: Artmed Panamericana, (Sistema de Educação Continuada a Distância, v.3), pp: 41-75.

16. Hoehn MM, Yahr MD (1967) Parkinsonism: onset, progression and mortality. Neurology 17(5): 427-442.

17. Bertolucci PHF, Brucki S, Campacci SR, Juliano Y (1994) 0 mini-exame do estado mental em uma população geral. Arq Neuropsiquiatr 52(1): 1-7.

18. Podsiadlo D, Richardson S (1991) The Timed up and Go - a Test of Basic Functional Mobility for Frail Elderly Persons. J Am Geriatr Soc 39(2): 142-148.

19. Miyamoto ST, Junior LJ, Berg KO, Ramos LR, Natour J (2004) Brazilian version of the Berg balance scale. Brazilian Journal of Medical and Biological Research 37(9): 1411-1421.
20. Karvonen MJ, Kentala E, Mustala O (1957) The effects of training on heart rate; a longitudinal study. Ann Med Exp Biol Fenn 35(3): 307-315.

21. (1997) I Consenso Nacional de Reabilitação Cardiovascular. Arq Bras Cardiol 69(4): 269-291.

22. (1991) Report World Hypertension League-Physical exercise in the management of hypertension: a consensus statement by the World Hypertension League. J Hypertens 9(3): 283-287.

23. Miyasato R, Batista CS, Peçanha T, Low DA, de Mello MT, et al. (2018) Cardiovascular Responses During Resistance Exercise in Patients With Parkinson Disease. PM R (18): 1-7.

24. Rocha RSB, Oliveira LS, Pena ESM , Caldas LCP, Elza SMP, Moreno MA (20170 Analysis of autonomic modulation of heart rate in patients with Parkinson's disease and elderly individuals submitted to game therapy training. Geriatrics \& Gerontology International 18(1): 20-25.

25. Mihci E, Kardelen F, Dora B, Balkan S (2006) Orthostatic heart rate variability analysis in idiopathic Parkinson's disease. Acta Neurologica Scandinavica 113(5): 288-293.

26. Tambosco L, Percebois-Macadré L, Rapin A, Nicomette-Bardel J, Boyer FC (2014) Effort training in Parkinson's disease: A systematic review. Annals of Physical and Rehabilitation Medicine 57(2): 79-104.

27. Palma JA, Carmona-Abellan MM, Barriobero N, Trevino-Peinado C, Garcia-Lopez M, et al. (2013) Is cardiac function impaired in premotor Parkinson's disease? A retrospective cohort study. Mov Disord 28(5): 591-596.

28. Aerts MB, Synhaeve NE, Mirelman A, Bloem BR, Giladi $\mathrm{N}$, et al. (2009) Is heart rate variability related to gait impairment in patients with Parkinson's disease? A pilot study. Parkinsonism \& Related Disorder 15(9): 712-715.

29. Shulman LM, Katzel LI, Ivery FM, Sorkin JD, Favors K, et al. Randomized Clinical Trial of 3 Types of Physical Exercise for Patients With Parkinson Disease. JAMA Neurol 70(2): 183-190.

30. Schenkman M, Moore CG, Kohrt WM, Hall DA, Delitto A, et al. (2018) Effect of High-Intensity Treadmill Exercise on Motor Symptoms in Patients With De 


\section{Neurology \& Neurotherapy Open Access Journal}

Novo Parkinson Disease. JAMA Neurology 75(2): 219226.

31. Pereira JAC, Gaiad TP, Santos AP (2016) Efeito do treinamento em circuito orientado para tarefa sobre o desempenho motor e a qualidade de vida de pacientes com doença de Parkinson: um estudo de casos. Rev Ter Ocup Univ São Paulo 27(3): 329-335.
32. Shah C, Beall EB, Frankemolle AM, Penko A, Phillips MD, et al. (2016) Exercise Therapy for Parkinson's Disease: Pedaling Rate is Related to Changes in Motor Connectivity. Brain Connect 6(1): 25-36.

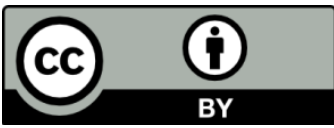

